\title{
Preliminary Study on the Undergraduate Specialty Structure Adjustment of General University in China
}

\author{
Wenbo Wang \\ School of Management, Dalian University of Technology \\ Dalian, China \\ Tong Li \\ Business Administration College of Dalian University \\ Dalian, China \\ E-mail: litong67@tom.com
}

\begin{abstract}
This article aims at the problem of deviation between the specialty structure of general university and the demand structure of market, and judges the state of employment rate by the single-value and standard deviation(x-S) control chart, then presents a specialty structure adjustment mechanism. The theories and methods of this article provide a quantified tool of undergraduate specialty structure adjustment for universities, and decrease the blindness of adjustment. Apply this mechanism to a certain university's computer science and technology specialty of Dalian, it achieved satisfying result.
\end{abstract}

\section{Introduction}

According to the figures released by Ministry of Education, from 2002 to 2005, the total number of university graduates was $1.45,2.12,2.8,3.4$ million, but the employment rate is only around $72 \%$. So the number of unemployed graduates was $435,635,675,912.6$ thousand in these years, and it is increasing.

Although a large number of university graduates can not find job successfully, the enrolment ratio of undergraduate is still very low in China. National Bureau of Statistics showed that the ratio was only $5.7 \%$ in our country, while developed countries was $30 \%-50 \%$, and the least developed countries was on average of $8.8 \%$. The number of current university students is unable to meet the needs of rapid economic and social development in our country.

So, there is a structural problem in university graduates employment. The unemployment of university graduates which took place in recent years is structural, it only showed in some subjects, but not all. All this reflected that the specialty structure adjustment of universities was lagged behind the rapid economic and social development in our country.

There are many researches of curriculum reform, education and economy structure adjustment, but few of them discussed how to link education structure with economy structure, and most of these studies belong to qualitative research, such articles that combine qualitative and quantitative methods are rare.

\section{The theoretical framework of specialty structure adjustment mechanism}

This article combines qualitative and quantitative methods, and considers from four aspects: market demand rate, enrollment rate, trend of employment rate, professional counterpart rate.

\subsection{Interpretation of the terms in mechanism}

A certain specialty's enrollment rate $=$ its enrollment number / total enrollment number $\times 100 \%$ (expressed by S);

A certain specialty's market demand rate $=$ the number of its market demand $/$ the number of total market demand $\times$ $100 \%$ (expressed by D);

Difference between supply and demand of a certain specialty $=$ its enrollment number - the number of its market demand (expressed by $\mathrm{S}-\mathrm{D}$, and Table 1 shows the numerical range of it);

The lowest enrollment rate of new specialty $=$ the lowest enrollment number of new specialty / total enrollment number $\times 100 \%$ (expressed by $\mathrm{N}_{\min }$ );

The lowest adjustment rate of enrollment number $=$ the lowest adjustment value when adjust a certain specialty's enrollment number / total enrollment number $\times 100 \%$ (expressed by $\mathrm{A}_{\min }$ ). 
Insert Table 1 Here

\subsection{Compare future market demand structure with university's specialty structure}

Firstly, investigate and analyze the state of future market demand. We must get the specialty list of future market demand from this step.

Then, analyze the specialty structure of market and university, figure out the market demand rate, university's enrollment rate, difference between supply and demand of these specialties (including market demand specialties and university's specialties). Based on these data, we will know which adjustment mechanism these specialties should belong to.

\subsection{Lack of specialty}

If the university don't have a certain specialty which market needs (i.e. $S=0$ and $D>0$ ), the university needs to consider whether to create this new specialty. Figure 1

\section{Insert Figure 1 Here}

shows the specific operation mode.

\subsection{Surplus of specialty}

If the university have a certain specialty which market demand rate is less than the lowest enrollment rate of new specialty (i.e. $\mathrm{S}>0$ and $\mathrm{D}<\mathrm{N}_{\min }$ ), the university needs to consider whether to delete this specialty. Figure 2 shows the specific operation mode.

(Note: analysis of employment rate is showed in chapter 3)

Insert Figure 2 Here

\subsection{Adjust the enrollment number of specialty}

If the university have a certain specialty which market demand rate is more than the lowest enrollment rate of new specialty (i.e. $\mathrm{S}>0$ and $\mathrm{D} \geq \mathrm{N}_{\min }$ ), the university needs to consider whether to adjust this specialty's enrollment number.

Furthermore, the maintained specialties by section 2.4 are also the objects of adjustment.

Figure 3 shows the specific operation mode (the content of ellipses located in the right side of this figure is the adjusted enrollment number).

Insert Figure 3 Here

\section{Analysis of employment rate}

We can use the single-value and standard deviation(x-S) control chart of quality control to analyze and estimate the state of employment rate.

\subsection{Determine control limit}

Employment rate of $\mathrm{n}$ years expressed by $\left(x_{1}, x_{2}, \ldots \ldots, x_{n}\right)$, and thus calculate those sample average $\bar{x}$ and sample standard deviation S:

$$
\bar{x}=\frac{1}{n} \sum_{i=1}^{n} x_{i}, \quad S=\sqrt{\frac{1}{n} \sum_{i=1}^{n}\left(x_{i}-\bar{x}\right)^{2}}
$$

According to the principle of $3 \sigma$, we will reckon the value of centerline, upper control limit and lower control limit, and then draw the control chart.

$$
\left\{\begin{array}{l}
U C L=\bar{x}+3 S \\
C L=\bar{x} \\
L C L=\bar{x}-3 S
\end{array}\right.
$$

Insert Figure 4 Here

\subsection{Analyze the control chart}

1). Normal state

(1) All the employment rates fall within the control limit, with no apparent regularity and tendency; 
(2) The number of employment rate located on both sides of the centerline are basically same;

(3) There are about more than $2 / 3$ employment rates fall within the $1 \sigma$ range around the centerline;

(4) The distribution of employment rates is more denser around centerline, and more sparser around the line of control limit.

If the employment rate of a certain specialty at a normal state, well then:

when $\bar{x} \geq 80 \%$, the rate "keep high"; when $50 \%<\bar{x}<80 \%$, the rate at "normal changing state"; when $\bar{x} \leq 50 \%$, the rate "keep low".

2). Abnormal state

(1) There are more than 7 continuous values appear on one side of the centerline;

(2) There are at least 10 values out of 11 continuous values appear on one side of the centerline;

(3) There are at least 12 values out of 14 continuous values appear on one side of the centerline;

(4) There are at least 14 values out of 17 continuous values appear on one side of the centerline;

(5) There are at least 16 values out of 20 continuous values appear on one side of the centerline;

(6) There are at least 2 values out of 3 continuous values appear around the line of control limit;

(7) There are at least 3 values out of 7 continuous values appear around the line of control limit;

(8) There are at least 4 values out of 10 continuous values appear around the line of control limit;

If these values "above the centerline" or "appear around the line of upper control limit": when $\bar{x} \geq 80 \%$, the rate "keep high"; when $50 \%<\bar{x}<80 \%$, the rate at "normal changing state"; when $\bar{x} \leq 50 \%$, the rate "keep low".

If these values "below the centerline" or "appear around the line of lower control limit": when $\bar{x} \geq 80 \%$, the rate at "normal changing state"; when $\bar{x}<80 \%$, the rate "keep low".

(9) There are more than 7 continuous values showed an upward trend, so the employment rate at an "increasing trend";

(10) There are more than 7 continuous values showed a downward trend, so the employment rate at a "declining trend";

\section{Demonstration analysis}

This article takes computer science and technology specialty of a certain general university of Dalian as an example. All data we used came from projects of "Survey and analysis of human resource demand of Dalian major projects and corporations" and "Research of the state and countermeasure of Dalian undergraduate employment".

\subsection{Analyze the data}

Market demand rate of computer science and technology specialty $\mathrm{D}=38.08 \%$, the lowest enrollment rate of new specialty of this general university $\mathrm{N}_{\min }=20 / 2332 \times 100 \%=0.86 \%$, we can see that $\mathrm{D}>\mathrm{N}_{\min }$, so this specialty belongs to the step of "adjust the enrollment number of specialty"(as shown in Figure 3).

\subsection{Whether to adjust the enrollment number}

This specialty's enrollment rate $\mathrm{S}=140 / 2332=6 \%$, so difference between supply and demand $\mathrm{S}-\mathrm{D}=6 \%-38.08 \%$ $=-32.08 \%$. The university's lowest adjustment rate of enrollment number $\mathrm{A}_{\min }=5 / 2332 \times 100 \%=0.21 \%$, according to the numerical range of Table 1, we know that this specialty belongs to the state "supply is less than demand". And then we will see this specialty's state of employment rate.

\subsection{Analysis of employment rate}

Insert Table 2 Here

Following values are calculated from above data.

$$
\left\{\begin{array}{l}
U C L=\bar{x}+3 S=112.47 \% \\
C L=\bar{x}=90.80 \% \\
L C L=\bar{x}-3 S=69.13 \%
\end{array}\right.
$$

Because the maximum of employment rate only to be $100 \%$, so $\mathrm{UCL}=100 \%$ is the natural upper limit.

Insert Figure 5 Here

From above figure we can see that the average of this specialty's employment rate $\bar{x}>80 \%$, and there are 7 continuous values above the centerline, so the employment rate of this specialty "keep high". Based on Figure 3, we will see that if a certain specialty's supply is less than the demand, and its employment rate keep high, its enrollment number $=$ its enrollment number of last year $\times 120 \%$. So the enrollment number of computer science and technology specialty of this university is $180 \times 120 \%=216$. 


\section{Conclusions}

The specialty structure adjustment mechanism in this article focus on the market, but there are so many considerations when the university adjusts its specialty structure, by no means limited to the market demand. So universities can take this mechanism as a reference, and take the results adjusted by this mechanism as one aspect of their specialty structure adjustment. The universities can set up a weight for the results, and then combine with other considerations, in this way, they can adjust their specialty structure comprehensively and exactly.

\section{References}

Bai. Limin. (2006). “Graduate Unemployment: Dilemmas and Challenges in China's Move to Mass Higher Education”, China Quarterly, Cambridge University Press, United Kingdom, Mar, pp. 128-144.

Gachon. Nicolas. (2008). "Participation, Democracy, and the Adjustment of Higher Education to the Market Economy", Education Canada, Education Canada, Canadian Education Association, Spring, pp. 45-45.

Harman. Kerry \& Bohemia. Erik. (2007). "Structure and Play: Rethinking Regulation in the Higher Education Sector", Industy and Higher Education, IP Publishing Ltd, London Oct, pp. 367-374.

Junfang Chen, Pei Huang \& Aiwen Zhang. (2004). Quality Control, Criterion Press of China, Beijing, Aug.

Lauwers. John. (2002). "Changing Structures of Leadership and Management in Higher Education”, Perspectives: Policy \& Practice in Higher Education, Routledge, United Kingdom, Jan, pp. 2-10.

Morgan. Anthony W. \& Kulivo. Nadezhda V. (2007). "Reform and Adaptation in Russian Higher Education", European Education, M.E. Sharpe Inc., New York, Fall, pp. 39-61.

Xuefei Zhao. (2005). "Superficial Research of Mismatched Education Expressed by Undergraduate Unemployment", China Economist, Social Science Institute of Shanxi, Taiyuan, Oct, pp. 101-103.

Table 1. Numerical range of the difference between supply and demand

\begin{tabular}{|c|l|}
\hline $\begin{array}{c}\text { supply and demand } \\
\text { are almost match }\end{array}$ & $\begin{array}{l}\mathrm{S}-\mathrm{D}<\mathrm{A}_{\min } \\
\mathrm{S}-\mathrm{D}>-\mathrm{A}_{\min }\end{array}$ \\
\hline supply is more than demand & $\mathrm{S}-\mathrm{D} \geq \mathrm{A}_{\min }$ \\
\hline supply is less than demand & $\mathrm{S}-\mathrm{D} \leq-\mathrm{A}_{\min }$ \\
\hline
\end{tabular}

Table 2. Employment rate of computer science and technology specialty in recent 10 years

\begin{tabular}{|c|c|c|c|c|}
\hline 1998 & 1999 & 2000 & 2001 & 2002 \\
\hline $85 \%$ & $88 \%$ & $89 \%$ & $93 \%$ & $92 \%$ \\
\hline 2003 & 2004 & 2005 & 2006 & 2007 \\
\hline $92 \%$ & $91 \%$ & $95 \%$ & $90 \%$ & $93 \%$ \\
\hline
\end{tabular}




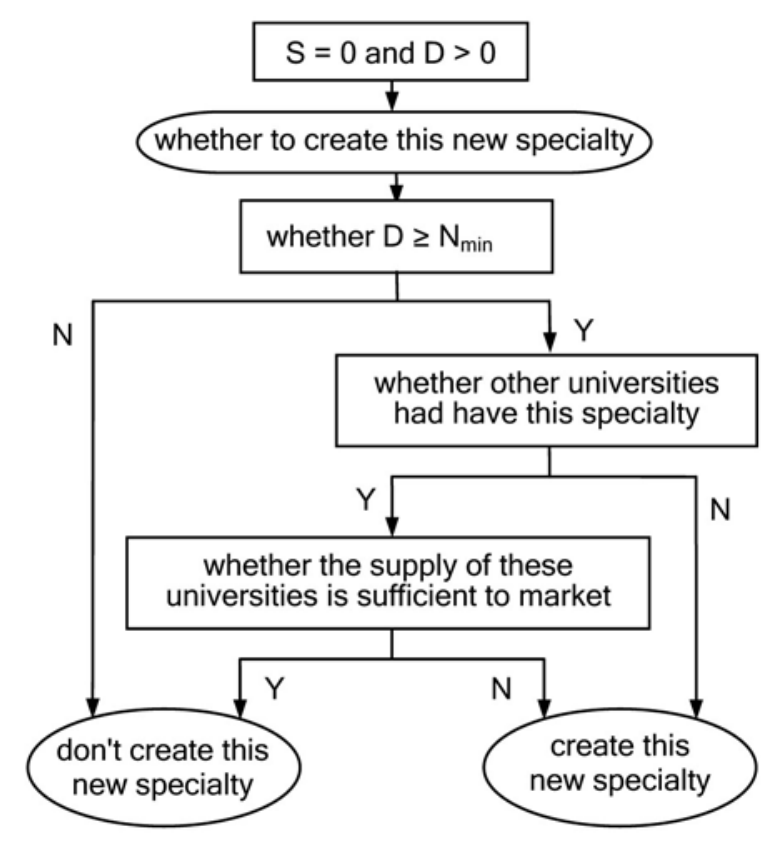

Figure 1. Flow of create new specialty

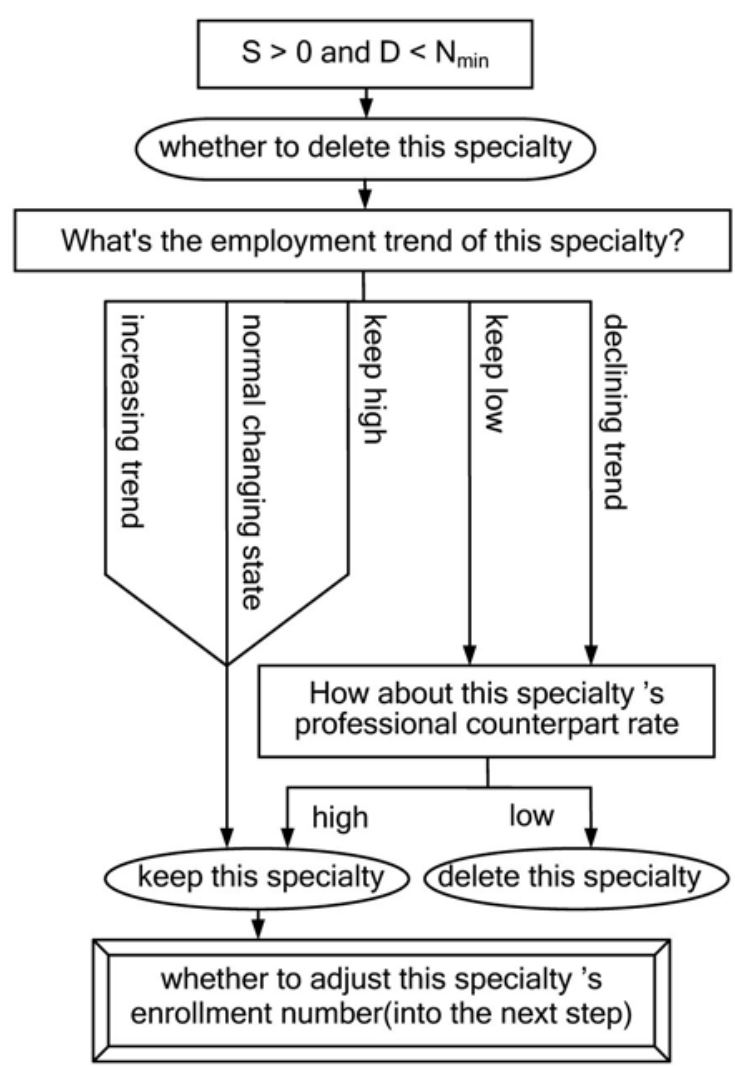

Figure 2. Flow of delete surplus specialty 


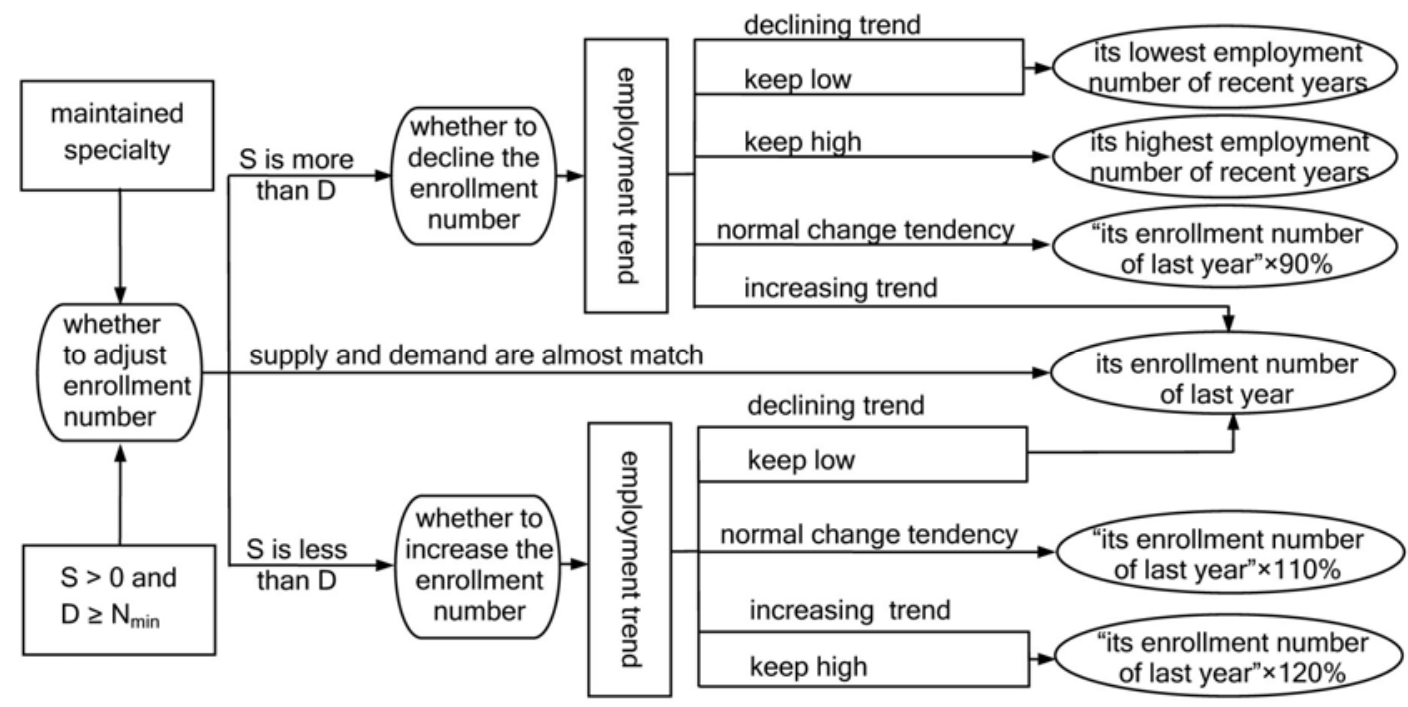

Figure 3. Flow of adjust specialty 's enrollment number

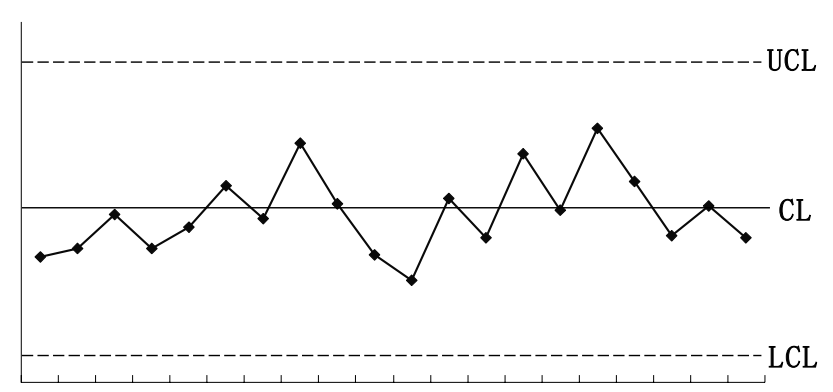

$\begin{array}{llllllllllllllllllll}88 & 89 & 90 & 91 & 92 & 93 & 94 & 95 & 96 & 97 & 98 & 99 & 00 & 01 & 02 & 03 & 04 & 05 & 06 & 07\end{array}$

Figure 4. The state of employment rate

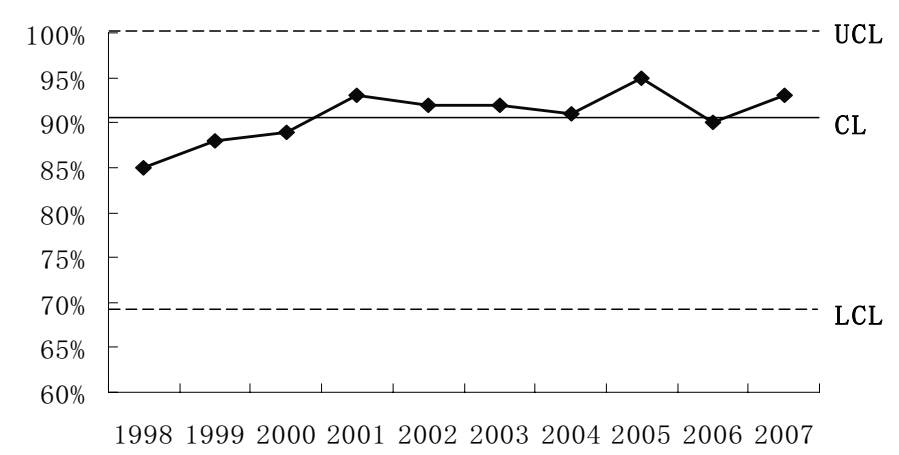

Figure 5. The control chart of employment rate 